\title{
Electrochemical immunosensor based on ensemble of nanoelectrodes for immunoglobulin IgY detection: Application to identify hen's egg yolk in tempera paintings
}

\author{
Fabio Bottari ${ }^{\mathrm{a}}$, Paolo Oliveri ${ }^{\mathrm{b}}$, Paolo Ugo ${ }^{\mathrm{a}, *}$ \\ a Department of Molecular Sciences and Nanosystems, University Ca' Foscari of Venice, S. Marta 2137, 30123 Venice, Italy \\ ${ }^{\mathrm{b}}$ Department of Pharmacy, University of Genoa, Via Brigata Salerno, 13, 16147 Genoa, Italy
}

\section{A R T I C L E I N F O}

\section{Article history:}

Received 5 July 2013

Received in revised form

21 August 2013

Accepted 6 September 2013

Available online 20 September 2013

Keywords:

Immunosensor

Nanoelectrode

Egg yolk

IgY

Voltammetry

Tempera paint

\begin{abstract}
A B S T R A C T
A nanostructured electrochemical biosensor for detecting proteins of interest in work of art, in particular in tempera paintings, is presented. To determine egg yolk we focus here on the determination of immunoglobulin IgY. The transducers are nanoelectrode ensembles (NEEs), prepared via membrane templated electroless deposition of gold. Because of their geometrical and diffusion characteristics, NEEs are characterized by significantly low detection limits, moreover they display the capability of capturing proteins by interaction with the polycarbonate membrane of the NEE. At first, the proteic component of the paint is extracted by ultrasonication in an aqueous buffer, then IgY is captured by incubation on the NEE. The immunoglobulin is detected by treatment with anti-IgY labeled with horse radish peroxidase (Anti-IgY-HRP). The binding of the Anti-IgY-HRP is detected by recording the electrocatalytic signal caused by addition of $\mathrm{H}_{2} \mathrm{O}_{2}$ and methylene blue. The sensor detection capabilities are tested by analyzing both paint models, prepared in the lab, and real samples, from paintings of the XVIII-XX century. Multivariate exploratory analysis is applied to classify the voltammetric patterns, confirming the capability to differentiate egg-yolk tempera from other kind of tempera binders as well as from acrylic or oil paints.
\end{abstract}

c) 2013 Elsevier B.V. All rights reserved.

\section{Introduction}

In the field of conservation of cultural heritage, the availability of analytical information on the materials used to produce works of art is crucial. As far as ancient paintings are concerned, the identification of the composition of painting layers furnishes valuable information on the pictorial technique used, authenticity, possible superimposition of later pictorial or varnish layers. All this information is necessary to guide the restoration intervention and to indicate the most suitable conservation conditions.

To this aim, many analytical methods based on the use of advanced instrumentation are presently available. However few tools allow the quick but reliable analysis of small samples performed directly in restoration laboratories by conservation scientists.

A painting is a complex analytical matrix composed by frame, support, priming and preparation, painting and finishing layers. The pictorial layer itself is a complex system composed by pigments (i.e. insoluble metal oxides or salts, organic pigments or lacquers) kept together by a binder. The nature of the binder determines the working behavior of the paint and the final characteristics of the work of art, not only from an esthetic viewpoint, but also as far as durability and

\footnotetext{
* Corresponding author. Tel.: + 39041234 8503; fax: + 390412348594.

E-mail address: ugo@unive.it (P. Ugo).
}

conservation are concerned. The binders most commonly used by Western artists include animal glue, casein, egg, drying oils, resins, natural gums and, more recently, synthetic materials such as acrylic polymers and others.

A particularly important painting technique is the tempera technique. This term indeed includes a wide range of painting media based on the use of water dispersible binders which, upon drying, become insoluble. The use of tempera techniques spans from the beginning of Christian era (for miniatures and religious icons) to modern painters (e.g. Böcklin, Giorgio de Chirico, Luigi Tito etc.) up to contemporary artists. The most classical tempera technique was described by Cennino Cennini in his XV century book "Il Libro dell'Arte" and it is based simply on mixing the finely grounded pigments with egg yolk. Other tempera techniques use whole egg or egg white, alone or mixed with flour or animal glue. Many artists used also to mix oily components to the classical tempera binders.

From an analytical viewpoint, identifying proteins from different animal sources is not an easy task. One approach is based on sequencing and identifying proteins on the basis of the presence of specific chemical components, using expensive spectroscopic (Casadio and Toniolo, 2001; Doménech-Carbò, 2008; Prati et al., 2010) and chromatographic or hyphenated mass spectrometric techniques (Colombini and Modugno, 2004; Marinach et al., 2004; Doménech-Carbò, 2008). An alternative approach is based on 
molecular recognition methods which exploit the reactivity of specific molecules present in the binder. Recently, immunosensors have been developed with the purpose of determining the presence of egg as pictorial binder. The use of antibodies in conservation science is not new; dating back to the 1960s-70s (Jones, 1962; Johnson and Packard, 1971). More recently, an immunofluorescence microscopy (IFM) method was proposed to identify ovalbumin (Kockaert et al., 1989) and casein (RamírezBarat and de la Viña, 2001); while Heginbotham et al. (2006) used both IFM and ELISA for the identification of ovalbumin. Assays based on chemiluminescence (Dolci et al., 2008; Sciutto et al., 2011) have been developed and many different natural compounds were detected by using ELISA or IFM (Vagnini et al., 2008; Cartechini et al., 2010; Palmieri et al., 2011). These researches opened new prospects for the application of immunosensors to the identification of pictorial binders, however they are targeted to detect ovalbumin, a protein present in high amount in egg albumen and yolk (Mann, 2007; Mann and Mann, 2008). A limit is that those methods cannot discriminate between albumen or whole egg tempera from egg yolk tempera.

In order to develop a sensor able to give specific information on the presence of egg yolk as the binder, in the present study we focus on a different analyte, namely, the glycoprotein immunoglobulin IgY which is the main serum immunoglobulin in chicken (Carlander et al., 1999) and, in chicken eggs, is present in the yolk at concentration of 5-10 $\mathrm{mg} \mathrm{mL}^{-1}$ (Chalghoumi et al., 2009; Dias da Silva and Tambourgi, 2010). It has a molecular mass of about $180 \mathrm{kDa}$ and its isoelectric point ranges between 5.7 and 7.6 (Chalghoumi et al., 2009). The IgY maintains its stability in a wide range of $\mathrm{pH}$ (from 4 to 12) while the thermal denaturation of the protein occurs only above $70{ }^{\circ} \mathrm{C}$. For these reasons, IgY is a suitable candidate to be exploited as a tracer useful to detect the presence of egg yolk in a sample.

The transducers used by us for developing IgY immunosensor, are the nanoelectrode ensembles (NEEs). NEEs are prepared via template electroless deposition of gold within the pores of a polycarbonate $(\mathrm{PC})$ track-etched membrane; the characteristics of the membranes (pore density and pore diameter) determine the voltammetric response of the electrodes (Menon and Martin, 1995; Ugo et al., 1996). When the boundaries of radial diffusion layers of each nanoelectrode overlap, the so called total overlap (TO) diffusion regime is achieved. NEEs prepared from commercial available track etched PC membranes typically operate under the TO regime. Under this regime, a peak dependant faradic current is recorded which is proportional to the geometric area $\left(A_{\text {geom }}\right)$, while the double layer charging current (the background current) depends only on the active area $\left(A_{\mathrm{act}}\right)$.

The high ratio between faradic and double layer charging current reflects in very high $\mathrm{S} / \mathrm{N}$ ratios so that NEEs are characterized by detection limits 2-3 orders of magnitude lower than those of macrolectrodes with the same geometric area (Brunetti et al. 2000; Ugo and Moretto, 2007). For biosensing purposes, another advantage of NEEs is the possibility of binding organic macromolecules, like proteins, to the PC of the electrode ensemble. On the surface of PC membrane there are several carboxylic groups, which interact with the amino terminations of amino-acids (Rucker et al., 2005; Silvestrini et al., 2011). Several biosensors have been recently developed exploiting this characteristic (Zamuner et al., 2008; Pozzi Mucelli et al., 2008; Silvestrini et al., 2013).

The detection scheme used in the present work is based on the protein binding capability of the PC of the NEEs and it is summarized in Scheme 1.

In step (A), IgY is captured by the NEE surface. In step (B), after blocking with BSA, the IgY captured by the NEE surface is incubated with anti-IgY labeled with HRP (Anti-IgY-HRP). Finally, in step (C), the presence of the label HRP, is detected by adding the enzyme substrate (namely, $\mathrm{H}_{2} \mathrm{O}_{2}$ ) and methylene blue (MB) as a suitable redox mediator (Pozzi Mucelli et al., 2008). At first the paint models prepared using recipes found in the classical treatise "Il Libro dell'Arte" of Cennino Cennini (1370-1440) as well as the recipes used by the modern Venetian painter Luigi Tito (19071991) were analyzed. The sensor was finally applied to characterize real samples taken from paintings spanning a time lag from XVIII to XX century.

Multivariate exploratory analysis was applied to the voltammetric profiles. The outcomes confirm that the information embodied in the signals is functional to characterize samples on the basis of the nature of the binder present in the pictorial media.

\section{Materials and methods}

Electrochemical measurements were carried out at room temperature with a $\mathrm{CH} 660$ potentiostat using a three-electrodes cell
A

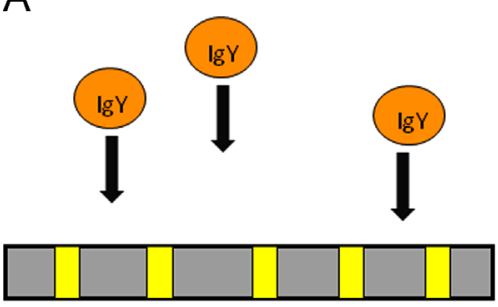

B

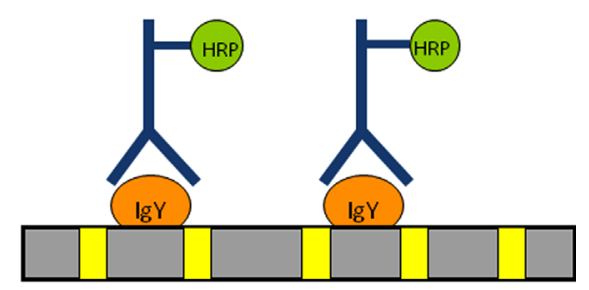

C

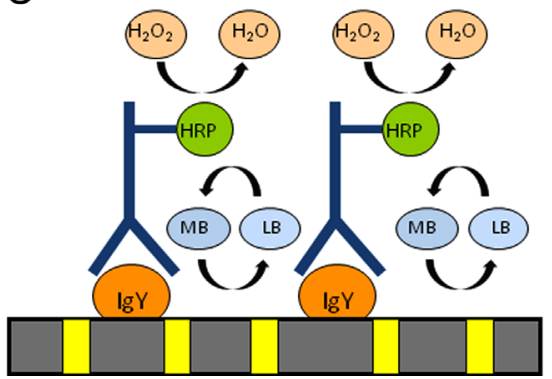

Scheme 1. Schematic representation of the analytical protocol. 
equipped with a platinum counter electrode and an $\mathrm{Ag} \backslash \mathrm{AgCl}(\mathrm{KCl}-$ saturated) reference electrode; the NEE was used as the working electrode. The polycarbonate template membranes are supplied by SPI Pore Filter ( $47 \mathrm{~mm}$ diameter, pore thickness $6 \mu \mathrm{m}$, pore diameter $30 \mathrm{~nm}$, pore density $6 \times 10^{8}$ pores $\mathrm{cm}^{-2}$ ). IgY (Chrome Pure IgY, whole molecule) was from Jackson Immunoresearch Laboratories; Anti-IgY-HRP was from Immunology Consultants Laboratory and Bovine Serum Albumin (BSA) was from SigmaAldrich. All other chemicals were reagent grade and used without further purification. NEEs were prepared by template gold electroless deposition in PC track-etched membranes according to the procedure developed by Menon and Martin (1995) and following updates (Pereira et al., 2006; De Leo et al., 2007; Ugo and Moretto, 2007). See Supplementary data for details.

\subsection{Paint model samples}

All paint model samples were prepared mixing the binder with Yellow Ocher $\left(\mathrm{Fe}_{2} \mathrm{O}_{3} \cdot \mathrm{H}_{2} \mathrm{O}\right)$. A single paint layer was applied on pure cellulose paper, using two tempera recipes found in "Il Libro dell'Arte" and three recipes from the painting notes of the Venetian painter Luigi Tito (1907-1991), summarized in Table S1, Supplementary data.

The analysis were performed also on sample of commercial oil (Maimeri) and acrylic (Liquitex) paint layers. The real samples were taken from painting belonging to private collections. List of samples and paintings are reported in Table 1.

\subsection{Analytical protocol}

The analyses were carried out on paint samples (10 mg for paint models, $1 \mathrm{mg}$ for real paintings) dispersed in $1 \mathrm{~mL}$ of $0.1 \mathrm{M}$ phosphate buffer, $\mathrm{pH} 7$, and treated by ultrasonication for $2 \mathrm{~h}$, to extract the proteinaceous compounds. Afterward the following procedure was adopted:

- Ten microliters of the extraction solution were deposited on the surface of a NEE and incubated for $30 \mathrm{~min}$ at room temperature, in a humidity chamber made by a sealed Petri's plate with wet filter paper on the bottom. Proteins, like IgY, are expected to bind on the carboxylic groups present on the PC surface (Zamuner et al., 2008; Pozzi Mucelli et al., 2008).

- The NEE was rinsed three times with $1 \mathrm{~mL}$ of phosphate buffer.

- The NEE was dipped in a blocking solution (1\% bovine serum albumin in phosphate buffer) for $30 \mathrm{~min}$ at room temperature on an orbital shaker plate.
- The electrode was rinsed three times with $1 \mathrm{~mL}$ of phosphate buffer.

- Ten microliters of $0.05 \mathrm{mg} \mathrm{mL}^{-1}$ Anti-IgY HRP in phosphate buffer were deposited onto the surface of the NEE and incubated for $30 \mathrm{~min}$ at room temperature in the humidity chamber.

- The NEE was rinsed three times with $1 \mathrm{~mL}$ of phosphate buffer.

- The NEE was dipped in the voltammetric cell containing $0.1 \mathrm{mM} \mathrm{MB}, 0.1 \mathrm{M}$ phosphate buffer, $\mathrm{pH} 7$.

- The $\mathrm{CV}$ was recorded at $50 \mathrm{mV} \mathrm{s}^{-1}$, initial potential $0.2 \mathrm{~V}$, vertex potential $-0.6 \mathrm{~V}$.

- $8 \mu \mathrm{L}$ of $1.2 \mathrm{mM} \mathrm{H}_{2} \mathrm{O}_{2}$ were added to the electrolyte solution.

- The CV was recorded under the above CV conditions.

\subsection{Multivariate exploratory analysis}

Multivariate analysis was applied to the whole voltammetric profiles recorded after addition of $\mathrm{H}_{2} \mathrm{O}_{2}$, considered as instrumental fingerprints of samples analyzed. In more detail, principal component analysis (PCA) was performed as exploratory method (Jolliffe, 2002). See Supplementary data for details.

\section{Results and discussion}

On the basis of previous studies (Pozzi Mucelli et al., 2008), MB was used as redox mediator suitable to shuttle electrons from NEE to the HRP label, bound to Anti-IgY. The dotted line CV in Fig. 1, recorded at a bare NEE, shows a well resolved reduction peak which, according to previous literature reports (Wopschal and Shain, 1967; Ye and Baldwin, 1988), is attributed to the two electron-one proton reduction of MB to the leuco form (LB). This reduction occurs via a rather complex ECE mechanism (Wopschal and Shain, 1967).

The dashed curve in the same figure shows only minor changes in the CV pattern as a consequence of the treatment of the NEE with IgY, plus BSA as blocking agent and Anti-IgY-HRP. Indeed, the cathodic reduction peak current $\left(\mathrm{Ip}_{\mathrm{c}}\right)$ decreases slightly as well as the associated anodic reoxidation peak $\left(\mathrm{Ip}_{\mathrm{a}}\right)$, with $\mathrm{Ip}_{\mathrm{a}} / \mathrm{Ip}_{\mathrm{c}}$ being close to 1 both at a bare NEE and on the modified NEE. When $1.2 \mathrm{mM} \mathrm{H}_{2} \mathrm{O}_{2}$ is added to the treated NEE, a dramatic change in voltammetric pattern is detected: the reduction current increases, the reoxidation peak disappears and the $\mathrm{CV}$ pattern becomes sigmoidally shaped (full line in Fig. 1). These features agree with the occurrence of an electrocatalytic process, which, on the basis of previous research (Pozzi Mucelli et al., 2008), involves the

Table 1

List of real samples analyzed.

\begin{tabular}{|c|c|c|c|c|}
\hline Name & Acronym & Description & Period & IgY presence \\
\hline \multirow[t]{2}{*}{ Adoration of the Magi } & IU1 & \multirow[t]{2}{*}{ Painting on panel } & \multirow[t]{2}{*}{ XVIII-XIX c. } & Positive \\
\hline & IU2 & & & Positive \\
\hline Landscape & OU1 & Oil on cardboard & First half of XX c. & Negative \\
\hline Still life & OU4 & Oil on plywood & $1960 s$ & Negative \\
\hline Nude & CU1 & Sketch on paper & $1970 \mathrm{~s}$ & Positive \\
\hline Adoration of the Magi & $\mathrm{I} 2$ & Painting on panel & XVII-XVIII c. & Positive \\
\hline Wooden torch-holder & RT1 & Wooden polychrome sculpture & XVI-XVII c. & Positive \\
\hline \multirow[t]{3}{*}{ Greek Statue } & T01 & \multirow[t]{3}{*}{ Paint on canvas panel } & \multirow[t]{3}{*}{ XIXc. } & Negative \\
\hline & TO2 & & & Negative \\
\hline & TO3 & & & Negative \\
\hline Child Jesus & BG1 & Wooden polychrome sculpture & XVI-XVII c. & Negative \\
\hline Madonna with child & IR1 & Painting on panel & About 1700 s & Negative \\
\hline Commercial oil paint & Oil & Produced by Maimeri & -------- & Negative \\
\hline Commercial acrylic paint & Acr & Produced by Liquitex & -ー-ー-ー-ー & Negative \\
\hline Commercial tempera paint & Tcomm & Produced by Maimer & -ー-ー-ー-ー- & Negative \\
\hline
\end{tabular}




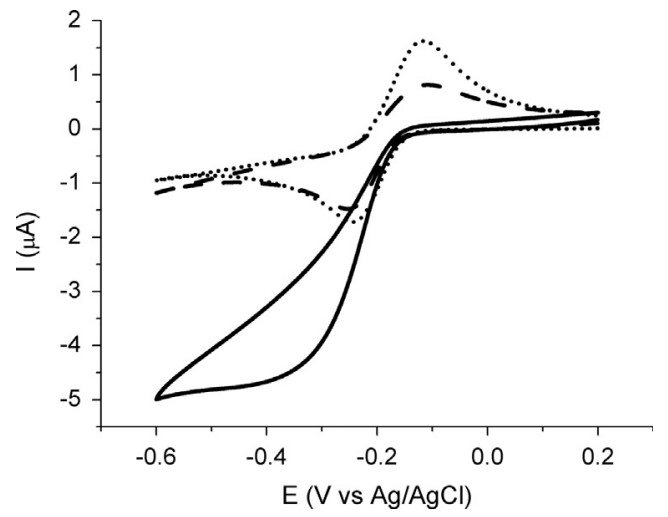

Fig. 1. Cyclic voltammogram in $0.1 \mathrm{mM} \mathrm{MB}, 10 \mathrm{mM}$ phosphate buffer, $\mathrm{pH} 7$, scan rate: $50 \mathrm{mV} \mathrm{s}^{-1}$. Before incubation (dotted line); after incubation with IgY (1.12 $\left.\mathrm{mg} \mathrm{mL}^{-1}\right), 1 \% \mathrm{BSA}$ and Anti-IgY-HRP $\left(0,05 \mathrm{mg} \mathrm{mL}^{-1}\right)$ (dashed line); after addition of $1.2 \mathrm{mM} \mathrm{H}_{2} \mathrm{O}_{2}$ (full line).

following reactions:

$\mathrm{MB}+2 \mathrm{e}^{-}+\mathrm{H}^{+} \rightarrow \mathrm{LB}$

$\mathrm{HRP}_{\text {red }}+\mathrm{H}_{2} \mathrm{O}_{2}+2 \mathrm{H}^{+} \rightarrow \mathrm{HRP}_{\mathrm{ox}}+2 \mathrm{H}_{2} \mathrm{O}$

$\mathrm{HRP}_{\mathrm{ox}}+\mathrm{LB} \rightarrow \mathrm{HRP}_{\text {red }}+\mathrm{MB}$

The CVs recorded at a NEE incubated only with BSA or with BSA and Anti-IgY-HRP (in both cases, with no IgY) overlap with the dashed line in Fig. 1, these CV patterns remain unaltered after addition of $\mathrm{H}_{2} \mathrm{O}_{2}$. These evidences indicate that, under these conditions, only BSA is eventually adsorbed on the NEE surface (Silvestrini et al., 2011), since the addition of $\mathrm{H}_{2} \mathrm{O}_{2}$ does not reflect in any further voltammetric change; this excludes any aspecific interaction between Anti-IgY-HRP and the NEE surface. Note that for all the above electrodes, after each incubation, the careful rinsing of the electrodes was performed before running the CV scan.

All these evidences indicate that:

1. IgY is captured by the NEE.

2. IgY, captured by the NEE, reacts efficiently with Anti-IgY-HRP which is consequently bound on the NEE surface.

3. Anti-IgY does not bind on the electrode surface in the absence of IgY.

4. The addition of $\mathrm{H}_{2} \mathrm{O}_{2}$ causes an electrocatalytic increase of the $\mathrm{MB}$ reduction current which could be potentially employed for analytical purposes.

Interestingly, the interactions of the NEE with the sample and with anti-IgY-HRP does not inhibit the cyclic voltammetric detection of $\mathrm{MB}$, so indicating that the proteins are bound mainly on the PC surface, in agreement with previous observations (Pozzi Mucelli et al., 2008), or if they adsorb on the Au surface of the NEE, they do not hinder the MB electrochemical reduction.

A series of experiments were performed incubating different NEEs with solution at different IgY concentrations. After incubation with Anti-IgY-HRP (and carefull rinsing) the electrodes were tested in electrolyte solution ( $0.1 \mathrm{M}$ phosphate buffer $\mathrm{pH}$ 7) containing $0.1 \mathrm{mM} \mathrm{MB}$. CV were recorded at 3 different scan rate $(20-50-100 \mathrm{mV} / \mathrm{s})$ before and after the addition of $\mathrm{H}_{2} \mathrm{O}_{2}$. The parameter analytically useful for identifying $\operatorname{IgY}$ is the electrocatalytic current increment $\left(\Delta i_{\text {cat }}\right)$ defined as:

$\Delta i_{\text {cat }}=\operatorname{Ip}_{\mathrm{c}}(\mathrm{MB})_{\text {with no } \mathrm{H}_{2} \mathrm{O}_{2}}-I$ catalytic $(\mathrm{MB})_{\text {with } \mathrm{H}_{2} \mathrm{O}_{2}}$
At the investigated scan rate (namely 100, 50 and $20 \mathrm{mV} \mathrm{s}^{-1}$ ), $\Delta i_{\text {cat }}$ shows a sharp dependence on IgY concentration in low concentration range ( $\leq 0.1 \mathrm{mg} \mathrm{mL}^{-1}$ ) while it tends to an asymptotic behavior for IgY concentration higher than $0.5 \mathrm{mg} \mathrm{mL}^{-1}$. Such a trend confirm once again the capturing of IgY by the NEE surface since a surface saturation effect is observed. The best compromise between sensibility and peak separation is achieved using a scan rate of $50 \mathrm{mV} \mathrm{s}^{-1}$. (See Fig. S1 in Supplementary data). Concerning the optimization of Anti-IgY-HRP concentration, experiments performed at different concentrations with a constant IgY concentration $\left(0.02 \mathrm{mg} \mathrm{mL}^{-1}\right)$ indicated that the increase of Anti-IgY concentration from 0.02 to $0.05 \mathrm{mg} \mathrm{mL}^{-1}$ reflects in an approximately four-fold increase in $\Delta i_{\text {cat }}$. There is no further increase for higher concentration so suggesting $0.05 \mathrm{mg} \mathrm{mL}^{-1}$ Anti-IgY-HRP as the optimum concentration.

\subsection{Paint model samples}

The main binders examined in model samples were egg yolk, albumen, commercial linseed oil and commercial acrylic. While for the egg yolk and albumen tempera the water extract was clear and it was applied on the electrode without any further treatment, for the oil and acrylic sample, the extract appeared turbid. Preliminary experiments indicated that the direct application of such turbid extract on the NEE compromised the functioning of the electrode. This problem was overcome by centrifugation of the extract to precipitate the particles and obtaining a clear surnatant which was applied on the NEE.

After blocking, the electrodes were incubated with Anti-IgYHRP, accurately washed and used as working electrode in the electrochemical cell containing phosphate buffer and MB. The voltammetric pattern recorded for the 4 extract and in different steps of the analytical process, are shown in Fig. 2.

The dotted line CVs in Fig. 2 shows the MB signal recorded at NEE before incubation with the extraction solution; these curves are shown as reference CVs. The dashed lines report the CVs recorded at NEE after incubation with the extract samples, blocking with BSA and incubated with Anti-IgY-HRP. Finally, the full line CVs refer to voltammograms recorded after adding $1.2 \mathrm{mM} \mathrm{H}_{2} \mathrm{O}_{2}$.

Fig. 2A shows that for the yolk tempera (TYolk) extract, an electrocatalytic behavior is clearly observed when $\mathrm{H}_{2} \mathrm{O}_{2}$ is added. On the other hand, Fig. 2B indicates that, for the albumen tempera (TAlb), the voltammogram maintains the reoxidation peak and the reduction current grows only slightly, so excluding the occurrence of the electrocatalytic sequence which involves Anti-IgY-HRP and $\mathrm{H}_{2} \mathrm{O}_{2}$ and electrogenerated LB.

These results indicate that the reaction between IgY and AntiIgY-HRP gives a positive response only for the egg yolk tempera and not for the egg white extract. Indeed, IgY is present in the egg yolk and not in the albumen.

Fig. 2C and D shows that a completely different behavior is observed after incubation and immunoreaction of the oil (acronym: Oil) and acrylic paint sample (Acr). For Oil, the CV recorded at the NEE in the absence of $\mathrm{H}_{2} \mathrm{O}_{2}$ differs quite significantly for the reference curve obtained at a bare NEE. The cathodic peak current increases as well as $\left(E_{\mathrm{p}}-E_{\mathrm{p} \mid 2}\right)$ values and $\Delta E_{\mathrm{p}}=\mathrm{Ep}_{\mathrm{f}}-\mathrm{Ep}_{\mathrm{b}}$ separation, where $E_{\mathrm{p}}$ is the peak potential, $E_{\mathrm{p} / 2}$ is the half peak potential and the subscripts $f$ and $b$ refer to signals recorded in the forward and backward sweep, respectively. Interestingly, this pattern does not change upon addition of $1.2 \mathrm{mM} \mathrm{H}_{2} \mathrm{O}_{2}$. These evidences indicate that Anti-IgY-HRP is not bound onto the NEE, since IgY is not present. Moreover, the large peak-to-peak separation, together with the sloping shape of the voltammetric peaks detected in Fig. 2C and D, suggest increased capacitance and resistance of the NEE, which could be due to adsorption or etching of the NEE surface by some component of the extract. In any case, 
A

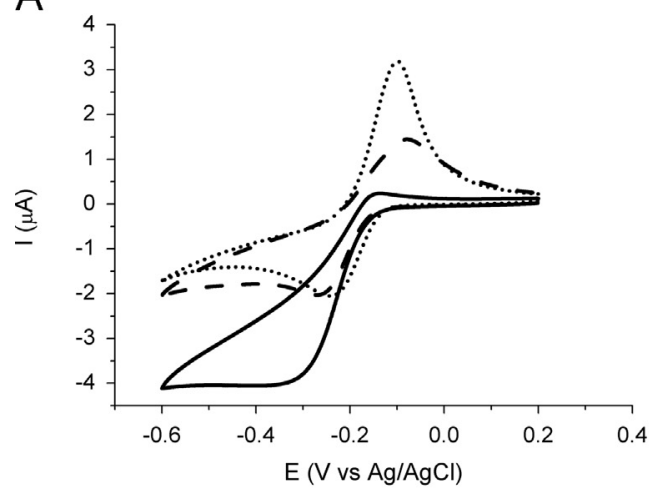

C

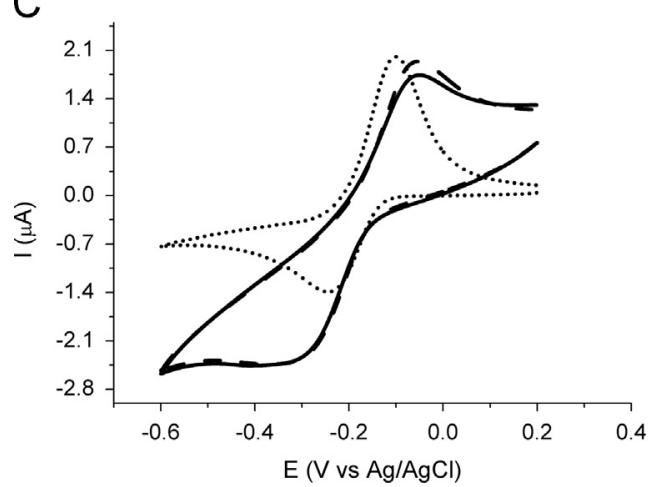

B

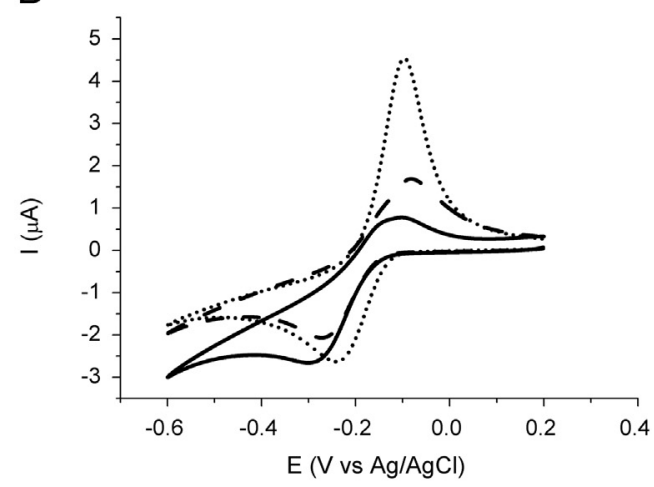

D

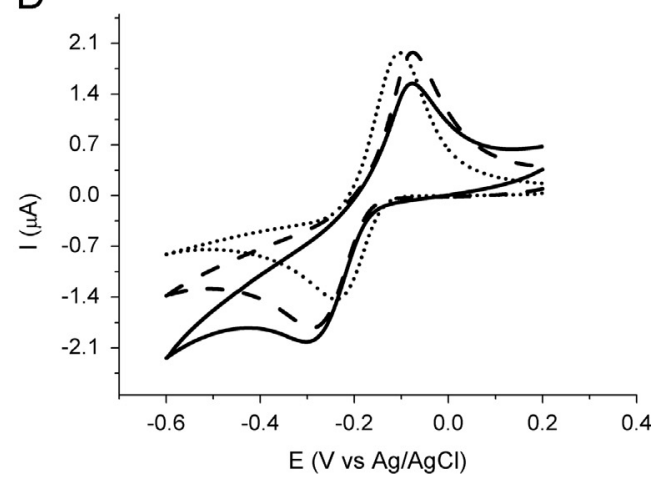

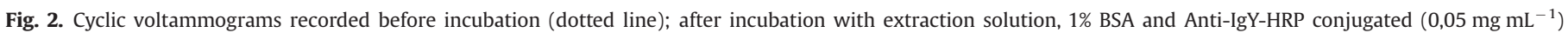
(dashed line); after addition of $1.2 \mathrm{mM} \mathrm{H}_{2} \mathrm{O}_{2}$ (full line). (A) Yolk tempera, (B) Albumen tempera, (C) Oil, and (D) Acrylic. Other conditions as in Fig. 1.

these features do not change by adding $\mathrm{H}_{2} \mathrm{O}_{2}$, therefore, they are not related to any IgY/Anti-IgY-HRP interaction.

The Acr sample displays a behavior intermediate between the albumen and the oil sample, with a slight increase in cathodic peak current after incubation and a very light further increase after addition of $\mathrm{H}_{2} \mathrm{O}_{2}$. Conversely, the anodic peak remains always well detectable. These slight effects due to the $\mathrm{H}_{2} \mathrm{O}_{2}$ addition to the albumen and acrylic samples are probably related to some minor side reaction between $\mathrm{H}_{2} \mathrm{O}_{2}$ and other components of the extract, whose effect is anyway very different and much less important than the one caused by the electrocatalytic cycle described by reactions $1-3$. It is worth pointing out that also model samples of tempera grassa (TGr and T1, see Table S1), egg and flour tempera (T2), flour and glue tempera (T3) were examined by the same procedure. Relevant CVs are reported in Supplementary data. For these cases of complex binders it is observed that the tempera grassa and egg and flour tempera show an electrocatalytic behavior comparable to that of yolk tempera, while flour and glue tempera do not. This agrees with the evidence that tempera grassa and egg and flour tempera contain egg yolk while flour and glue tempera does not. A sample of modern tempera paint commercially available (Tcomm) gives negative response, suggesting that the binder does not contain egg yolk.

\subsection{Application to real artworks}

The analyses on real paint samples were carried out on several paintings that belong to private collectors. Four samples of wooden icons of XVII-XVIII century and 2 samples of wooden polychrome sculptures from XVI-XVII century were analyzed. Three samples from the same painting from XIX century were also analyzed. These samples were taken from different layers: one from the ground layer, one from the original painting layer and the last one from a recent repainting. To complete the set of real samples, also three samples from modern paintings were analyzed; namely, two oil on cardboard and one sketch on paper, both of XX century. The list of samples are reported in Table 1, together with relevant sample acronyms; the CVs and a brief description of all samples are reported in the Supplementary data. Fig. 3 shows typical voltammograms representative of the CV behavior recorded on some real paint sample; two from paintings (IU1 and OU4) and two for wooden polychrome sculptures (BG1 and RT1).

The samples IU1 and RT1 (Fig. 3A and B) show an electrocatalytic current increase, when $\mathrm{H}_{2} \mathrm{O}_{2}$ is added to the NEEs incubated with the sample extract and anti-Ig-Y-HRP, as above described. The detection of the electrocatalytic current agrees with the presence of egg yolk in these paint samples; note that also another sample (IU1) from the same artwork gave a similar result (see CVs in Supplementary data). On the other hand, the CVs relevant to different samples, namely RT1 and BG1 (Fig. 3C and D, respectively), show $\mathrm{CV}$ patterns different from those of samples IU1 and OU4, but comparable with those of the oil paint model samples. The $\Delta E_{\mathrm{p}}$ and $\left(E_{\mathrm{p}}-E_{\mathrm{p} / 2}\right)$ values increase sensibly together with the cathodic peak current; note that the addition of $\mathrm{H}_{2} \mathrm{O}_{2}$ does not cause any further change, so suggesting that IgY/Anti-IgYHRP were not captured by the NEE.

The analyses carried out on paint model samples and samples from real paintings provided sets of analytical data, suitable for a more precise definition of the type of binder that is being analyzed. The main discriminating factor which indicates whether a sample contains an egg yolk based binder or not is the appearance of electrocatalytic process between MB and HRP. However, also other characteristics gained for the CV patterns can be helpful to further characterization of the sample. Table 2 lists four of these characteristics useful to this aim, all inserted in a tentative diagnostic scheme. 
A

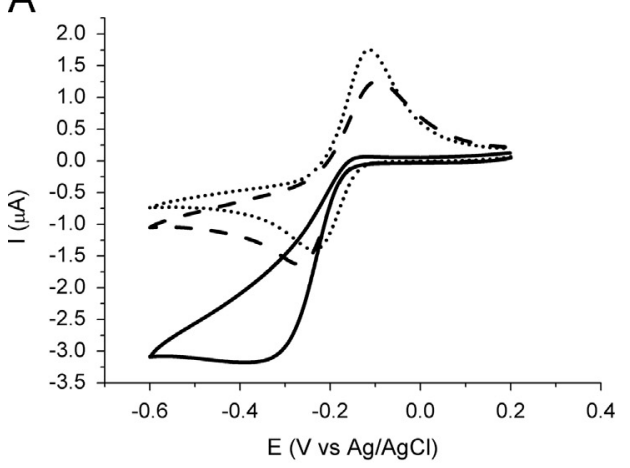

C

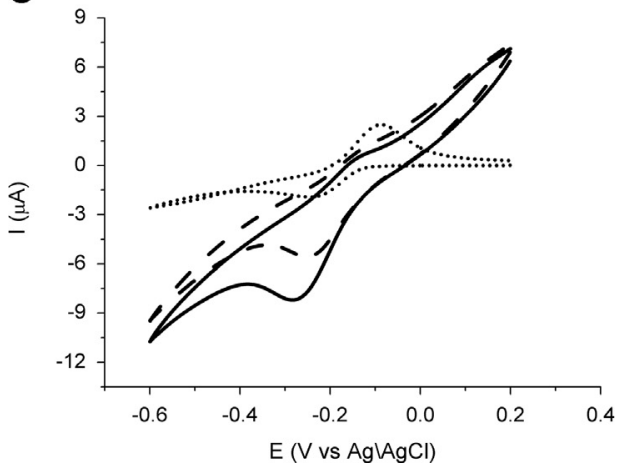

B

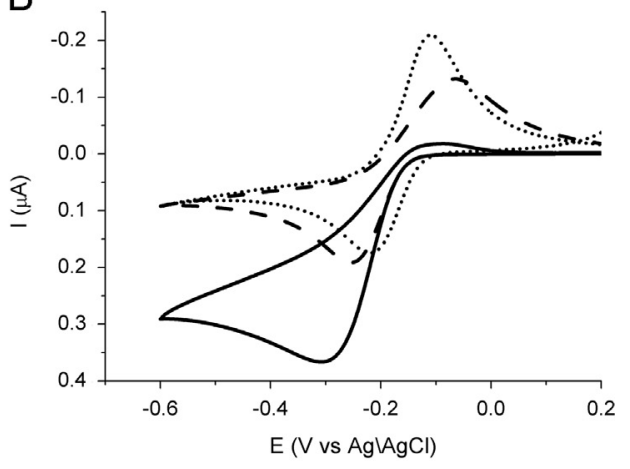

D

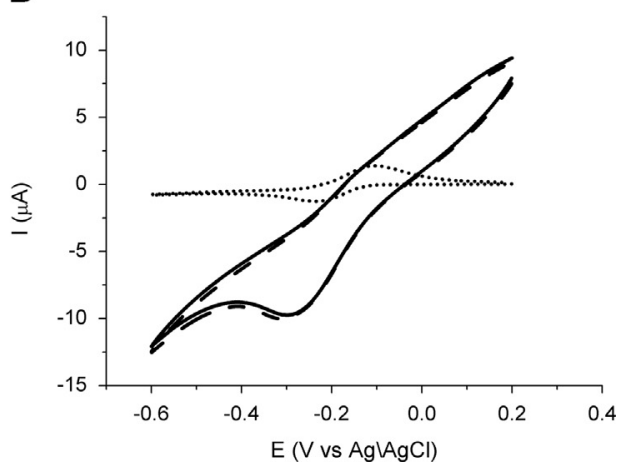

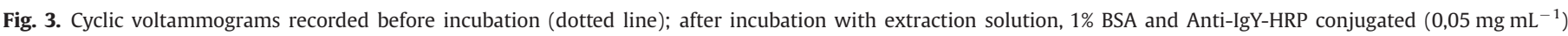
(dashed line); after addition of $1.2 \mathrm{mM} \mathrm{H}_{2} \mathrm{O}_{2}$ (full line). (A) IU1, (B) RT1, (C) BG1, and (D) OU4. Other conditions as in Fig. 1.

Table 2

Tentative diagnostic scheme based on the changes in the voltammetric patterns caused by the addition of $\mathrm{H}_{2} \mathrm{O}_{2}$.

\begin{tabular}{|c|c|c|c|c|}
\hline Painting Binder & Cathodic peak & Anodic peak & CV pattern & $\mathrm{H}_{2} \mathrm{O}_{2}$ effect \\
\hline Egg-yolk tempera & Significant increase & Disappears & Sigmoidal (catalytic) & Dramatic \\
\hline Other tempera & Slight increase & Slight decrease & Peak shaped & Almost negligible \\
\hline Oil & Increase & Almost unchanged & Peak with ohmic distortion & Completely negligible \\
\hline Acrylic & Slight increase & Slight decrease & Peak shaped & Almost negligible \\
\hline
\end{tabular}

From the exam of the scheme one can conclude that the convergence of all four factors, allow one to identify the presence of egg yolk in the paint layers. Among the examined samples such a positive convergence was found for samples IU1, IU2, CU1, I2, RT1, T1, T2, TGr and TYolk. Interestingly, this analysis point out that also other binders can be identified by the response the proposed analytical procedure, as it is the case of the oil binder; the $\mathrm{CV}$ recorded with the NEE in these samples show indeed the special features represented typically by the dashed and full line in Fig. $3 C$ and D. This is not due to any specific interaction of the NEE with any protein nor antibody, but it is related to a more generic kind of interaction between the NEE and the extract. On the basis of these observations and in order to extract the maximum analytical information for the sample, all the voltammetric data were further examined by performing Principal Component Analysis (PCA), as described below.

\subsection{Principal component analysis (PCA)}

PCA was applied to the raw voltammetric patterns analyzed as components of a data matrix structured with 24 rows (samples) and 1600 variables (currents measured at each sweep potential). The samples acronym and characteristic are listed in Tables 1 and S1 and in the above text. Both paint model and real artwork samples were included therein, in order to provide a comprehensive overview of the potentiality of the method in characterizing samples on the basis of presence/absence of egg yolk. The voltammograms processed by multivariate analysis were those recorded after addition of $\mathrm{H}_{2} \mathrm{O}_{2}$.

At first, signals were transformed by means of a standard normal variate (SNV) transform aimed at minimizing unwanted systematic differences among different measurements (Oliveri et al., 2010). Then, data were mean-centred column-wise and submitted to PCA. The score plot on the two lowest-order principal components is shown in Fig. 4A; samples which resulted positive to the egg yolk presence on the basis of the criteria in Table 2, are indicated as squared data points in the plot, while all the other are shown as circled data. A clear differentiation between samples positive to egg yolk vs. negative ones is clearly evidenced by the plot, with both of the principal components being involved in such a differentiation.

By a joint examination of the score plot (Fig. 4A) and the loading plot (Fig. 4B), it is possible to highlight the original variables (namely, the regions of the CVs) that are most involved in the characterization of samples containing egg yolk. They correspond to the current values gained in the -0.3 to $-0.5 \mathrm{~V}$ potential region, which are found - in the loading plot - to be opposite (with respect to the axis origin) to the direction in which 
A

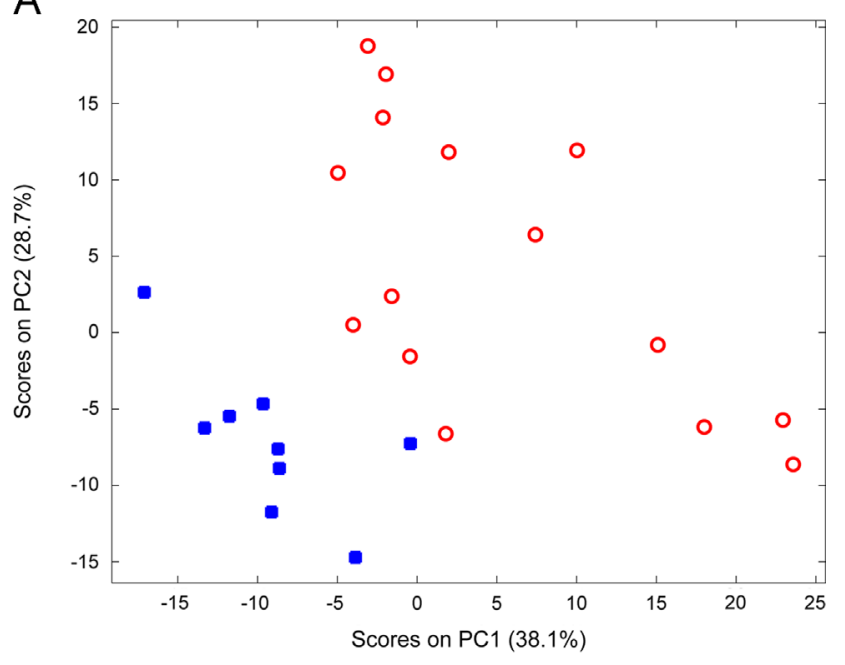

B

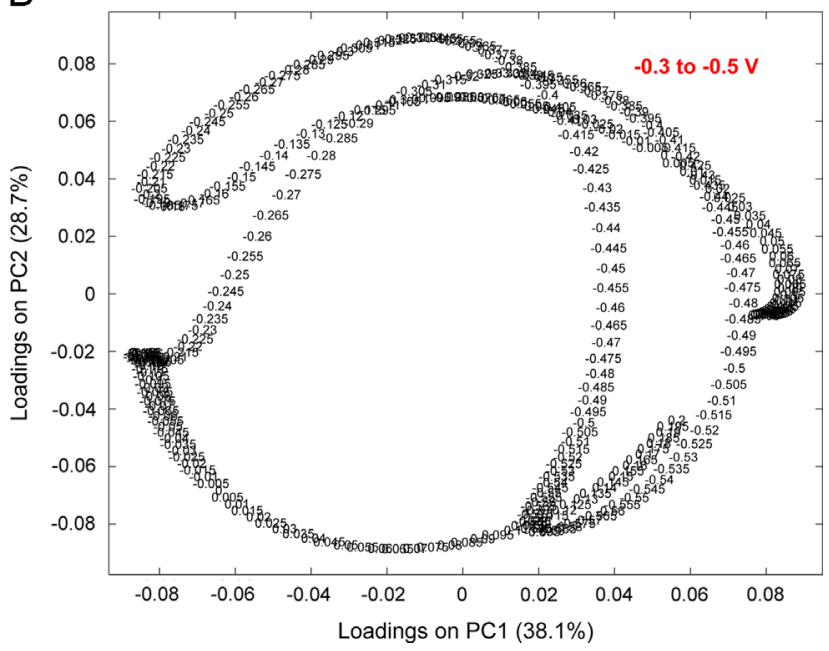

Fig. 4. Graphical output of PCA performed on CV recorded after addition of $\mathrm{H}_{2} \mathrm{O}_{2}$. (A) Score plot showing the differentiation between positive (solid squares) and negative (circles) samples. (B) Loading plot showing the original variables most involved in the differentiation.

the positive samples are localized within the score plot (solid squares in Fig. 4A).

Such an inverse correspondence is due to the fact that current values are negative in this potential range, which is, indeed, the part of the CV where the rise of the catalytic current is eventually observed.

The outcomes of PCA clearly confirm that the method proposed is a valuable tool for identifying egg yolk tempera in real paint samples of different nature.

\section{Conclusions}

This approach to the analysis of ancient paint binders is able to conjugate the specificity of immunochemical techniques with the rapid and cost affordable electrochemical detection. The use of a direct approach, in which the antigen is bound directly on the transducer surface, reduces the analytical steps and the reagents required. Another important advantage is the use of NEEs, which furnish well resolved $\mathrm{CV}$ patterns, with high $\mathrm{S} / \mathrm{N}$ ratios and which demonstrate very interesting IgY capturing capability, related to the high affinity of proteins for PC (Silvestrini et al., 2013). From a general bioanalytical and biosensing viewpoint, this is the first report describing an electrochemical immunosensor suitable for IgY detection. This seems an interesting achievement, taking into account the increasing use of IgY for advanced immune diagnostic and immunotherapy (Dias da Silva and Tambourgi, 2010).

Concerning the particular application studied here, i.e. paint binder identification, the analysis of the CVs allows a satisfactory distinction between the patterns obtained from samples containing IgY from those which do not contain such a protein. A reliable data analysis can be performed either using the simple diagnostic scheme illustrated in Table 2 or using a more sophisticated, but more precise PCA method. In principle, if suitable antibodies be available, a similar procedure could be extended also to the detection of other proteins of interest in the field of cultural heritage study and conservation.

\section{Acknowledgments}

Financial support by MIUR-Rome, (Project PRIN 2010AXENJ8) is acknowledged. We thank Giovanna Niero (conservator in Noale, Venezia) for providing some of the real samples and for skillful technical support and expertise.

\section{Appendix A. Supplementary material}

Supplementary data associated with this article can be found in the online version at http://dx.doi.org/10.1016/j.bios.2013.09.025.

\section{References}

Brunetti, B., Ugo, P., Moretto, L.M., Martin, C.R., 2000. Journal of Electroanalytical Chemistry 491, 166-174.

Carlander, D., Stalberg, J., Larsson, A., 1999. Journal of Medical Sciences 104, 179-190.

Cartechini, L., Vagnini, M., Palmieri, M., Pitzurra, L., Mello, T., Mazurek, J., Chiari, G. 2010. Accounts of Chemical Research 43, 867-876.

Casadio, F., Toniolo, L., 2001. Journal of Cultural Heritage 2, 71-78.

Chalghoumi, R., Beckers, Y., Portetelle, D., Théwis, A., 2009. Biotechnology, Agronomy, Society and Environment 13 (2), 295-308.

Colombini, M.P., Modugno, F., 2004. Journal of Separation Science 27, 147-160.

De Leo, M., Pereira, F.C., Moretto, L.M., Scopece, P., Polizzi, S., Ugo, P., 2007. Chemistry of Materials 19, 5955-5964.

Dias da Silva, W., Tambourgi, D.V., 2010. Veterinary Immunology and Immunopathology 135 (2010), 173-180.

Dolci, L.S., Sciutto, G., Guardigli, M., Rizzoli, M., Prati, S., Mazzeo, R., Roda, A., 2008. Analytical and Bioanalytical Chemistry 392, 29-35.

Doménech-Carbò, M.T., 2008. Analytica Chimica Acta 621, 109-139.

Heginbotham, A., Millay, V., Quick, M., 2006. Journal of the American Institute for Conservation 45, 89-105.

Johnson, M., Packard, E., 1971. Studies in Conservation 16, 145-164.

Jolliffe, I.T., 2002. Principal Component Analysis, second ed. Springer, New York.

Jones, P.L., 1962. Studies in Conservation 7, 10-16.

Kockaert, L., Gausset, P., Dubi-Rucquoy, M., 1989. Studies in Conservation 34 (4), $183-188$.

Mann, K., Mann, M., 2008. Proteomics 8, 178-191.

Mann, K., 2007. Proteomics 7, 3558-3568.

Marinach, C., Papillon, M.C., Pepe, C., 2004. Journal of Cultural Heritage 5, 231-240.

Menon, V.P., Martin, C.R., 1995. Analytical Chemistry 67, 1920-1928.

Oliveri, P., Casolino, C., Forina, M., 2010. In: Taylor, S. (Ed.), Chemometric Brains for Artificial Tongues. Advances in Food and Nutrition Research, Academic Press, Burlington, pp. 57-117.

Palmieri, M., Vagnini, M., Pitzurra, L., Rocchi, P., Brunetti, B.G., Sgamellotti, A. Cartechini, L., 2011. Analytical and Bioanalytical Chemistry 399, 3011-3023.

Pereira, F.C., Moretto, L.M., De Leo, M., Boldrin Zanoni, M.V., Ugo, P., 2006. Analytica Chimica Acta 577 (1), 16-24.

Pozzi Mucelli, S., Zamuner, M., Tormen, M., Stanta, G., Ugo, P., 2008. Biosensors and Bioelectronics 23, 1900-1903.

Prati, S., Joseph, E., Sciutto, G., Mazzeo, R., 2010. Accounts of Chemical Research 43, $792-801$.

Ramírez-Barat, B., de la Viña, S., 2001. Studies in Conservation 46, 282-288.

Rucker, V.C., Havenstrite, K.L., Simmons, B.A., Sickafoose, S.M., Herr, A.E., Shediac, R., 2005. Langmuir 21, 7621-7625.

Sciutto, G., Dolci, L.S., Buragina, A., Prati, S., Guardigli, M., Mazzeo, R., Roda, A., 2011. Analytical and Bioanalytical Chemistry 399, 2889-2897. 
Silvestrini, M., Schiavuta, P., Scopece, P., Pecchielan, G., Moretto, L.M., Ugo, P., 2011. Electrochimica Acta 56, 7718-7724.

Silvestrini, M., Fruk, L., Ugo, P., 2013. Biosensors and Bioelectronics 40, 265-270.

Ugo, P., Moretto, L.M., 2007. Template deposition of metal. In: Zoski, C.G. (Ed.), Handbook of Electrochemistry. Elsevier, Amsterdam, pp. 678-709.

Ugo, P., Moretto, L.M., Bellomi, S., Menon, V.P., Martin, C.R., 1996. Analytical Chemistry 68, 4160-4165.
Vagnini, M., Pitzurra, L., Cartechini, L., Miliani, C., Brunetti, B.G., Sgamellotti, A., 2008. Analytical and Bioanalytical Chemistry 392, 57-64.

Wopschal, R.H., Shain, I., 1967. Analytical Chemistry 39, 1527-1534.

Ye, J., Baldwin, R.P., 1988. Analytical Chemistry 60 (20), 2263-2268.

Zamuner, M., Pozzi Mucelli, S., Tormen, M., Stanta, G., Ugo, P., 2008. European Journal of Nanomedicine 1, 33-36. 